\title{
Soil-structure interaction for the seismic design of the Messina Strait Bridge
}

\author{
Luigi Callisto $^{\mathrm{a}, *}$, Sebastiano Rampello ${ }^{\mathrm{a}}$, Giulia M.B. Viggiani ${ }^{\mathrm{b}}$ \\ a University of Rome La Sapienza, Department of Structural and Geotechnical Engineering, via Eudossiana 18, 00184 Roma, Italy \\ ${ }^{\mathrm{b}}$ University of Rome Tor Vergata, Rome, Italy
}

\section{A R T I C L E I N F O}

\section{Article history:}

Received 27 July 2012

Received in revised form

5 March 2013

Accepted 30 May 2013

Available online 30 June 2013

Keywords:

Soil-structure interaction

Seismic design

Bridge foundations

Dynamic analysis

\begin{abstract}
A B S T R A C T
This paper illustrates an approach to the study of the seismic soil-structure interaction that was developed at the verification stage of the design of the Messina Strait Bridge in order to validate its seismic behaviour. It consisted of a series of two-dimensional, plane strain numerical analyses on models that included, in addition to the embedded foundation elements, a simplified structural description of the bridge towers: simplified structural models were specifically designed to reproduce the first vibrations modes of the towers, that were deemed to have the most significant influence on the system's dynamic response. Non-linear dynamic analyses were carried out in the time domain, studying the effects of two different natural records, each characterised by three orthogonal components of the soil motion. In the first part of the paper, essential information is provided about the foundations layout, the main properties of the foundation soil resulting from the in situ and laboratory investigation, and the assessment of the liquefaction potential. Then, the numerical models are discussed in some detail, with an emphasis on the modelling of the soil and of the structural elements. For sake of conciseness, details are provided only for one of the two shores. The results obtained with the present approach shed some light on the complex coupling between the soil's and the structure's behaviour, evidencing the significant role that the embedded, massive foundations of the bridge play in the dynamic response of the system. The computed time-histories of the displacements of the foundation elements are used to assess the seismic performance of the bridge.
\end{abstract}

(c) 2013 Elsevier Ltd. All rights reserved.

\section{Introduction}

Predicting the seismic response of a structure entails the analysis of a complex system, including wave propagation from a deep bedrock through the soil and into the foundation and the superstructure elements. The available analysis tools can be subdivided into direct and substructure approaches. The most common is the substructure approach, in which the problem is subdivided into its main principal elements, that are analysed independently and then combined to evaluate the complete solution. This technique requires the evaluation of the foundation input motion corresponding to a massless structure and of the impedance functions describing the stiffness and damping of the foundation elements; then, a dynamic analysis is performed in which the structure is supported by a compliant base and is subjected to the foundation input motion [1]. Although the substructure method uses superposition and is rigorously valid only for linear systems, non-linearity can be dealt with, for

\footnotetext{
*Corresponding author. Tel.: +39 64458 5980; fax: +39 644584792.

E-mail address: luigi.callisto@uniroma1.it (L. Callisto).
}

instance using domain reduction methods [2,3] and iterative procedures.

A substructure approach may not be fully adequate in many real cases. For instance, if the problem outline is complex, involving slopes, varying water levels, inclined layering, etc., the description of the foundation's response through equivalent visco-elastic impedance matrices may be misleading. Also, when a significant mobilization of the soil strength can be anticipated, it is difficult to deal with soil non-linearity through an iterative approach. In this case it would be desirable to use a direct method, in which a numerical analysis is carried out that includes explicitly the subsoil, the foundation elements and the superstructure, describing the respective mechanical behaviour with appropriate constitutive models.

Several factors make a direct approach difficult to implement and some of these reflect the different practice adopted by the structural and geotechnical engineers: the three-dimensionality of most structures, that contrasts with the practice of geotechnical specialists to deal with two dimensional, plane-strain conditions; the description of the earthquake effects in the soil deposits as waves propagating in a continuum material, as opposed to the modelling of structures as discrete systems with a finite number of 
degrees of freedom; the use of plasticity models for soils, in opposition with elasticity models mostly adopted in structural analyses.

This paper illustrates a specific case in which the geotechnical and structural practices were brought together, studying the seismic soil-structure interaction with a direct approach in which the computations were made feasible through a number of simplifying assumptions concerning both the soil and the structural modelling. The case studied is the suspension bridge across the Messina Strait, which is to connect Sicily with mainland Italy. An exhaustive description of the design of the bridge, including a compendium of the previous studies, may be found in Brancaleoni et al. [4]. In the following, the case is introduced through a brief description of the bridge substructures, an illustration of the geotechnical properties of the foundation soils, and a comment on their liquefaction potential; the development of the calculation models that were used at a final verification stage of the detailed design of the bridge is then described. It is shown that the computed results illustrate effectively the main characters of the seismic behaviour of the soil-structure system. The results of the analysis were used to assess the seismic performance of the bridge foundations; they could also be transferred back to the structural global model of the bridge for additional time-domain structural analyses that implicitly account for soil-structure interaction. For sake of conciseness, and to avoid unnecessary repetition, the illustration is mostly limited to the bridge foundations on the Sicily shore.

\section{Soil profile and foundation layout}

Fig. 1 shows a schematic elevation drawing of the Messina Bridge; it has a central span of $3300 \mathrm{~m}$, while the towers have a height of $381 \mathrm{~m}$. The Sicily and Calabria towers have twin embedded cylindrical foundations with a diameter of $55 \mathrm{~m}$ and $48 \mathrm{~m}$, respectively, and a depth of about $20 \mathrm{~m}$. In the transverse direction, the two cylindrical foundations are connected with a stiff box beam having a depth of $15 \mathrm{~m}$ from ground level. An extensive jet-grouted area is planned below the foundations, with a constant thickness of $23 \mathrm{~m}$ on the Sicily side and a thickness varying from $11 \mathrm{~m}$ to $36 \mathrm{~m}$, down to the Pezzo Conglomerate (see point 4 below) on the Calabria side; this treatment consists of secant jet-grouted columns with a nominal diameter of $1.6 \mathrm{~m}$. Lateral soil is also jet-grouted within a distance of $30-40 \mathrm{~m}$ from the foundation perimeter, for a thickness of about $33 \mathrm{~m}$ on the Sicily side and of $21 \mathrm{~m}$ to $40 \mathrm{~m}$ on the Calabria side. The lateral jetgrouted columns are arranged in a hexagonal array and cover $42 \%$ of the treated area. Jet-grouting has the purpose of inhibiting seismic liquefaction in the coarse-grained foundation soils. The anchorages are massive reinforced concrete blocks, with longitudinal dimensions of $99 \mathrm{~m}$ and $90 \mathrm{~m}$, respectively, extending to a depth of about $44 \mathrm{~m}$.

In the following sections, the discussion is mainly limited to the conditions at the Sicily shore, where, starting from ground level, the following soil deposits are encountered:

1. Coastal deposits: sand and gravel with little or no fine content. The thickness of this formation decreases moving inwards from the coastline, varying from about $80 \mathrm{~m}$ at the tower location to about $45 \mathrm{~m}$ at the terminal structure.

2. Messina Gravels/Terrace Deposits: gravel and sand with occasional silty levels, with a thickness of about $140 \mathrm{~m}$ and $200 \mathrm{~m}$, at the tower and anchor block location, respectively.

3. Continental Deposits/Vinco Calcarenite: clayey-sandy deposit, consisting of layers of silt or silt and sand, with significant gravel content/Bio-calcarenite and fossiliferous calcarenite, with thin silty layers.

4. Pezzo Conglomerate: soft rock, consisting of clasts of different dimensions in a silty-sandy matrix and sandstone.

5. Crystalline bedrock (Cristallino): tectonised granite.

Fig. 2 shows a schematic soil profile on the Sicily shore, limited to a depth of about $200 \mathrm{~m}$; within this depth, only the soil deposits

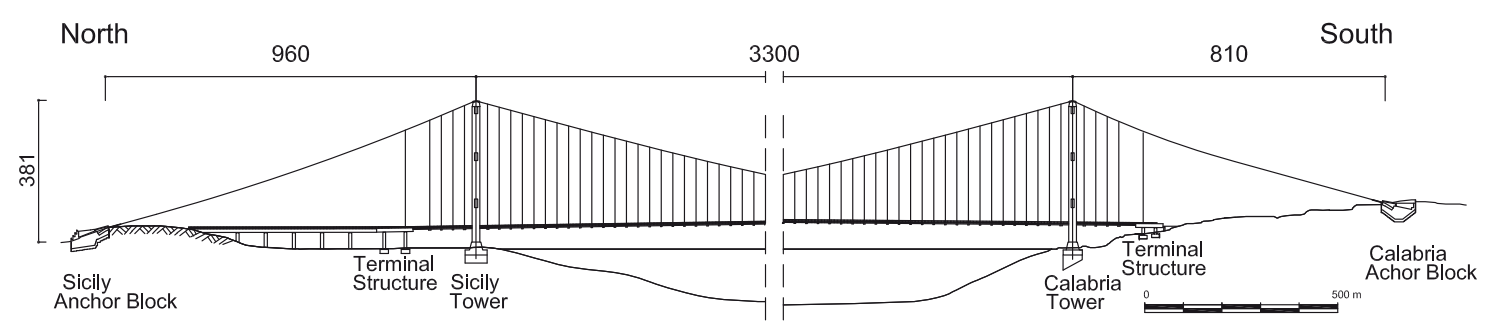

Fig. 1. Schematic longitudinal elevation of the Messina Strait Bridge.

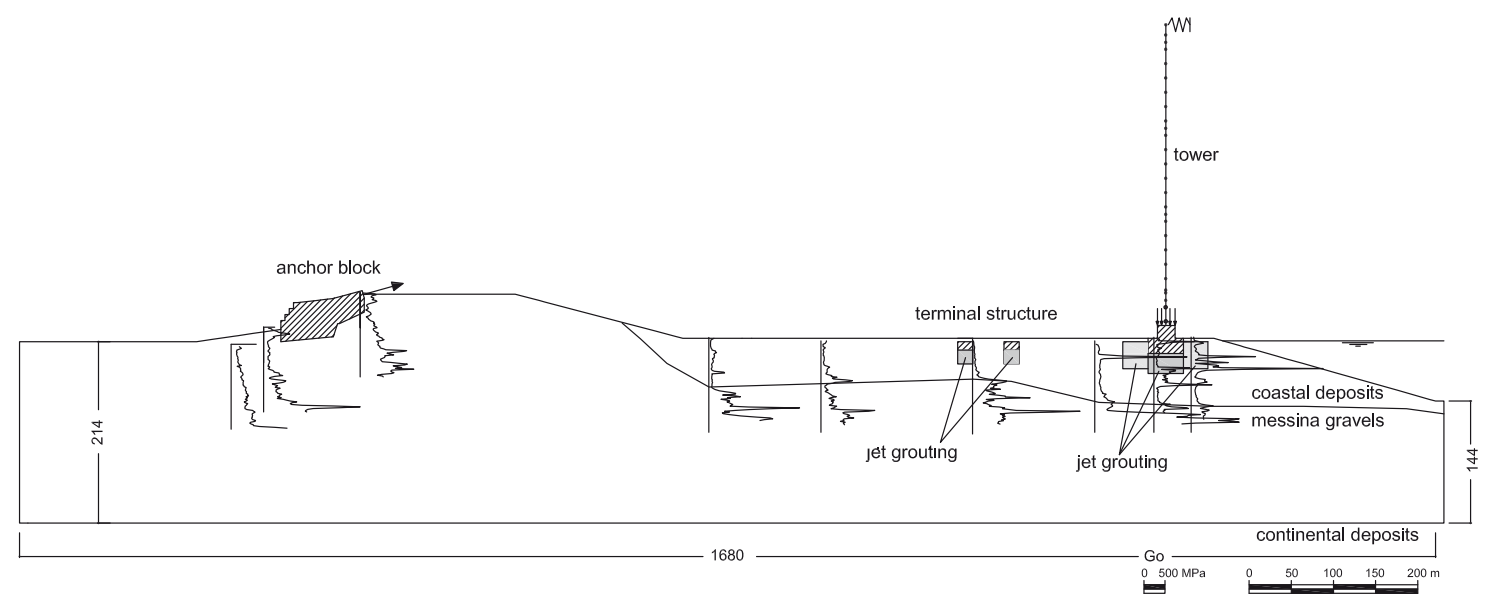

Fig. 2. Sicily shore: foundation soil with profiles of $G_{0}$, and boundaries of the calculation domain. 
a

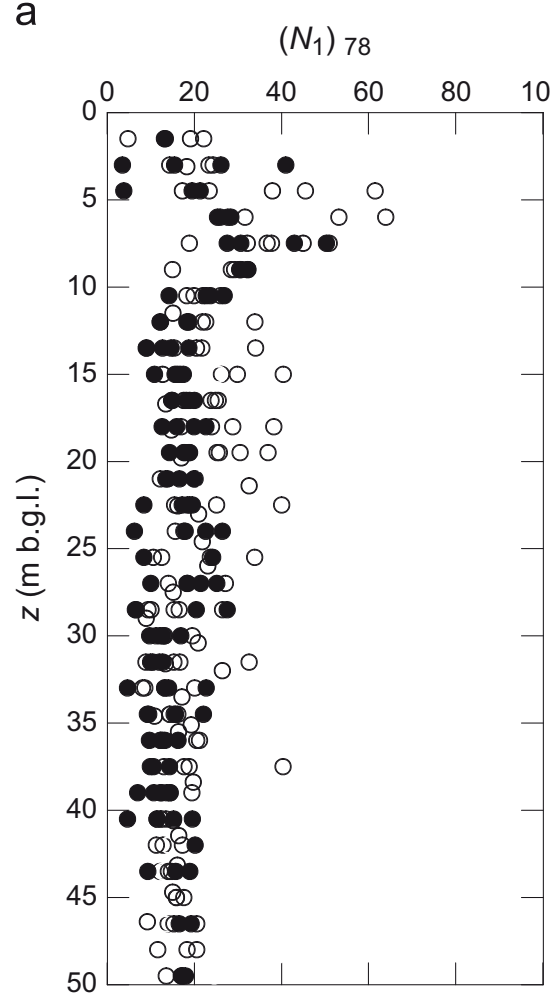

d

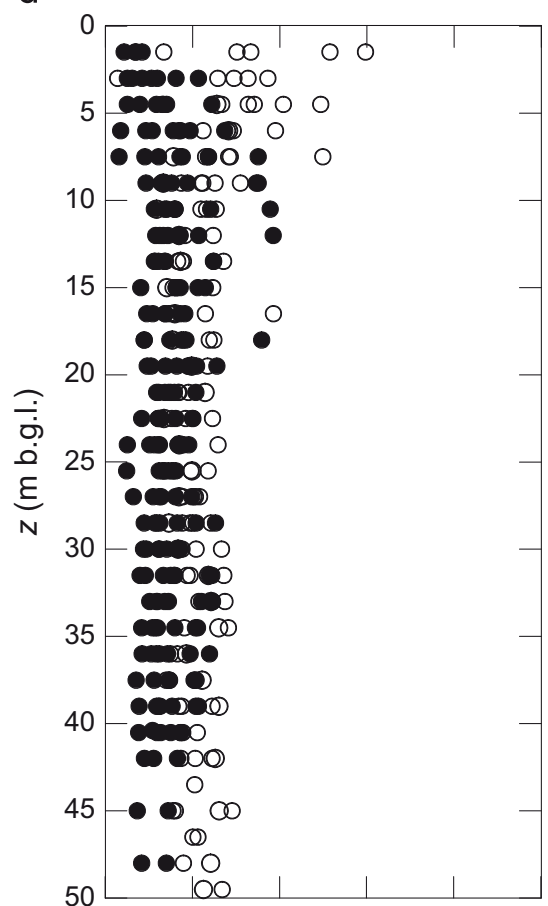

b

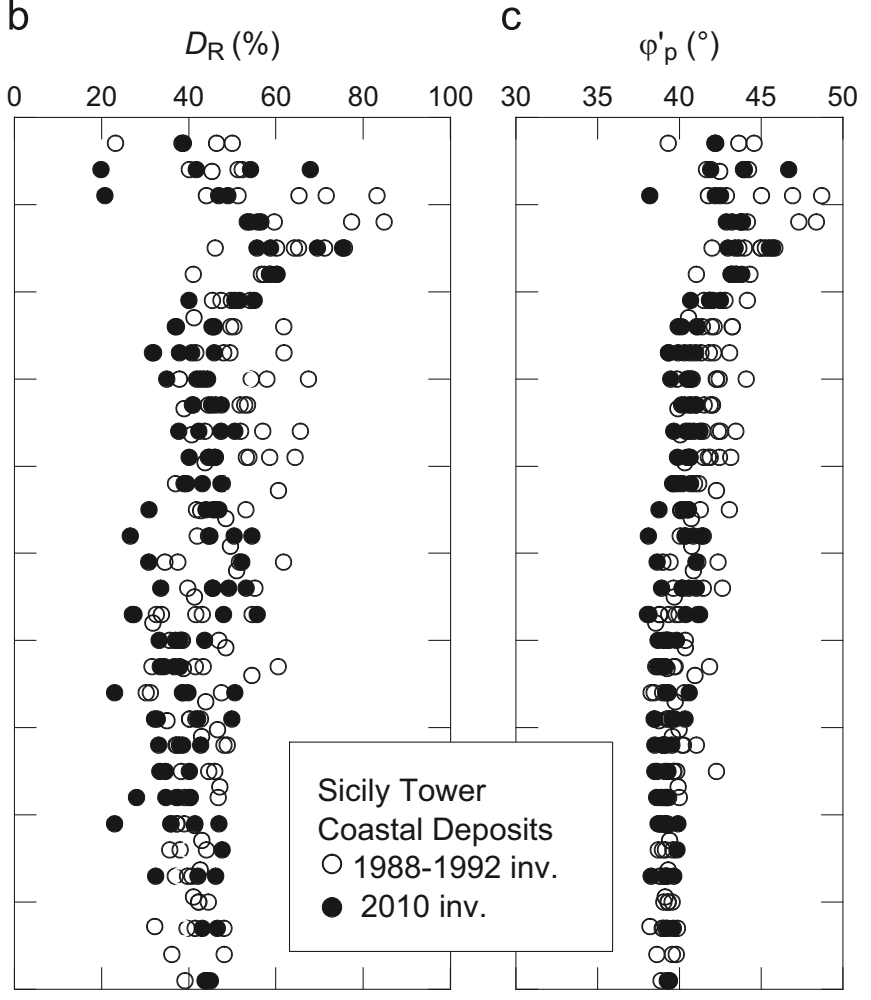

e

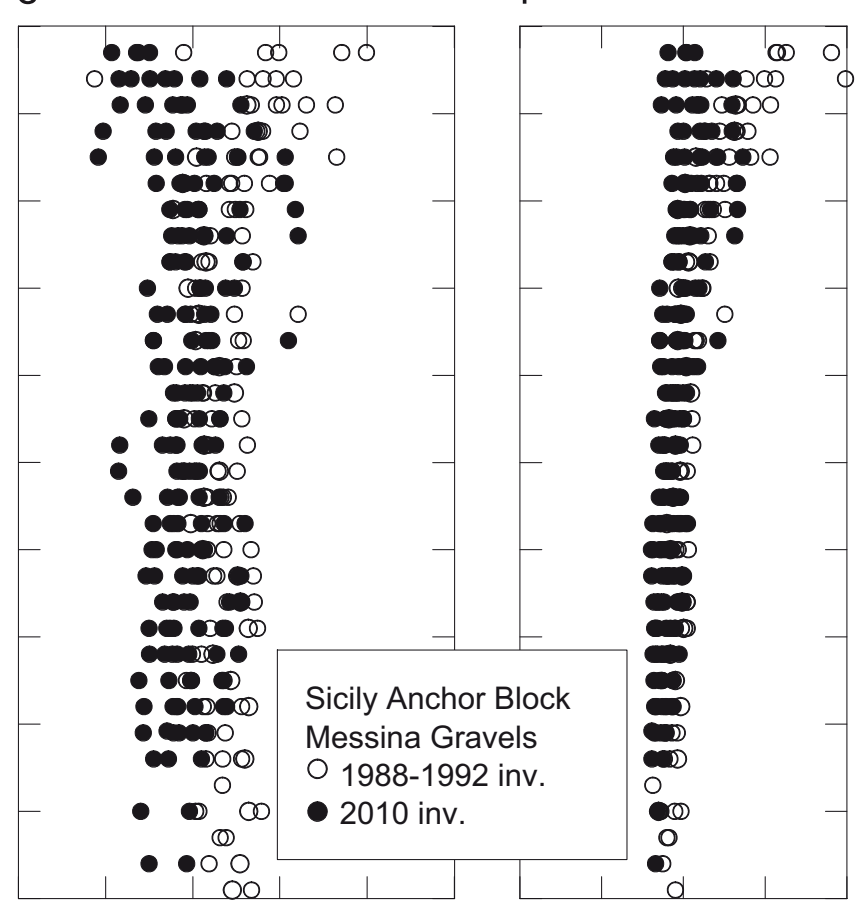

Fig. 3. Sicily shore: profiles of $\left(N_{1}\right)_{78}$ (a) and (d), relative density (b) and (e) and peak angle of shearing resistance (c) and (f) at the tower and anchor block locations.

No. 1 and 2 are encountered. The soil profile was investigated by a large number of boreholes and seismic wave surveys; Fig. 2 shows only the results of the cross-hole tests, in terms of profiles of small-strain shear stiffness, $G_{0}$, that proved very effective for the detection of the contact between the coastal deposits and the Messina gravels; these latter deposit has about the same grain size distribution as the coastal deposits but possesses a slight cementation that results in a larger stiffness and a smaller porosity. In Fig. 2, the soil profile is superimposed to the finite-difference calculation domain discussed in the following section (the calculation grid is omitted for clarity).

Fig. 3 shows the profiles of the results of a large number of dynamic penetration tests carried out with a standard and a large penetrometer [5] together with the profiles of the relative density $D_{\mathrm{R}}$ (obtained applying the relationship proposed by Cubrinovski and Ishihara [6]) and of the angle of peak shearing resistance $\varphi_{p}^{\prime}$ for the Sicily shore. In Fig. 3, $\left(N_{1}\right)_{78}$ is the blow-count normalised to account for the in situ effective stress and referred to an energy 
ratio of $78 \%$ [6]. Fig. 3(a)-(c) refer to the coastal deposits found below the tower foundations, while Fig. 3(d)-(f) refer to the Messina gravel that is present from ground level at the anchor block location. The relative density shows similar values at the tower and the anchor block locations: it varies within the range of $40 \%$ to $60 \%$ in the upper $25 \mathrm{~m}$, and shows some decrease at larger depths, reaching about $40 \%$ at $z=50 \mathrm{~m}$.

Large-diameter disturbed samples were retrieved from the coastal deposits and from the Messina gravels. In addition, at the Sicily tower location, a limited number of undisturbed samples were retrieved from the gravelly coastal deposits in the depth interval of 15-25 m, using the in situ freezing technique. Largediameter disturbed samples were reconstituted to a range of relative densities encompassing the in situ ones and were subjected to drained triaxial compression tests to evaluate the constant-volume strength envelope from the stationary parts of the tests [7]. The results of these tests are shown in the diagrams of Fig. 4(a), in which $q$ is the deviator stress and $\varepsilon_{a}, \varepsilon_{v}$ are the axial and volumetric strain, respectively. The corresponding constantvolume strength envelope is plotted in Fig. 4(b) in a $q-p^{\prime}$ plane, where $p^{\prime}$ is the mean effective stress; this plot includes also the results of three consolidated-undrained triaxial compression tests carried out on the undisturbed samples. The strength envelope indicates a value for the constant-volume angle of shearing resistance $\varphi_{\mathrm{cv}}^{\prime}=38^{\circ}$.

The information about $D_{\mathrm{R}}$, from the in situ testing, and $\varphi_{\mathrm{cv}}^{\prime}$ from the laboratory tests, was combined to derive the peak values of the angle of shearing resistance $\varphi_{p}^{\prime}$ through the relationship proposed by Bolton [8] that for the case at hand can be written as:

$\varphi^{\prime}{ }_{p}=\varphi^{\prime}{ }_{\mathrm{cv}}+3 D_{R}\left(10-\ln p^{\prime}\right)-1$

where $p^{\prime}$ is expressed in $\mathrm{kPa}$. The resulting profiles of $\varphi_{p}^{\prime}$ are shown in Fig. 3(c) and (f) for the tower and anchor block locations: values of $\varphi_{p}^{\prime}$ show a gentle decrease with depth resulting from the combined effect of an increase of mean effective stress and a decrease of relative density. In the top $25 \mathrm{~m}, \varphi_{p}^{\prime}$ ranges from $40^{\circ}$ to $45^{\circ}$, while at larger depths it tends progressively to the constantvolume value of $38^{\circ}$.

The profiles of small-strain shear modulus $G_{0}$ measured with nine cross-hole tests are shown in the longitudinal section of Fig. 2. The contact between the coastal deposits and the Messina gravels was located mainly through differences in $G_{0}$ : broadly, coastal deposits are characterised by a shear modulus smaller than about $200 \mathrm{MPa}$ that increases gently with depth, while larger values identify the Messina gravel.

\section{Seismic analyses}

\subsection{Seismic input}

The seismic input for the design of the substructures consisted of a selection of recorded acceleration time histories, there were considered representative of the near-field effects produced by the 1908 earthquake (with an estimated moment magnitude of 7.1) and consistent with the Italian Seismic Hazard map for a return period of 2475 years (Maximum Credible Earthquake). While a large number of acceleration time-histories were used at different stages of the design, the present discussion is restricted to the response to two specific recordings that were used in the soilstructure interaction analyses for the final verification stage of design: namely, the acceleration time histories corresponding to the records of Arcelik (Kocaeli earthquake 17 Aug 1999, Arcelik station) and DHFS (New Zealand Earthquake 03 Sept 2010, Darfield station). Both records were taken to be representative of a stiff outcrop motion. Fig. 5 shows the elastic response spectra (at 5\%
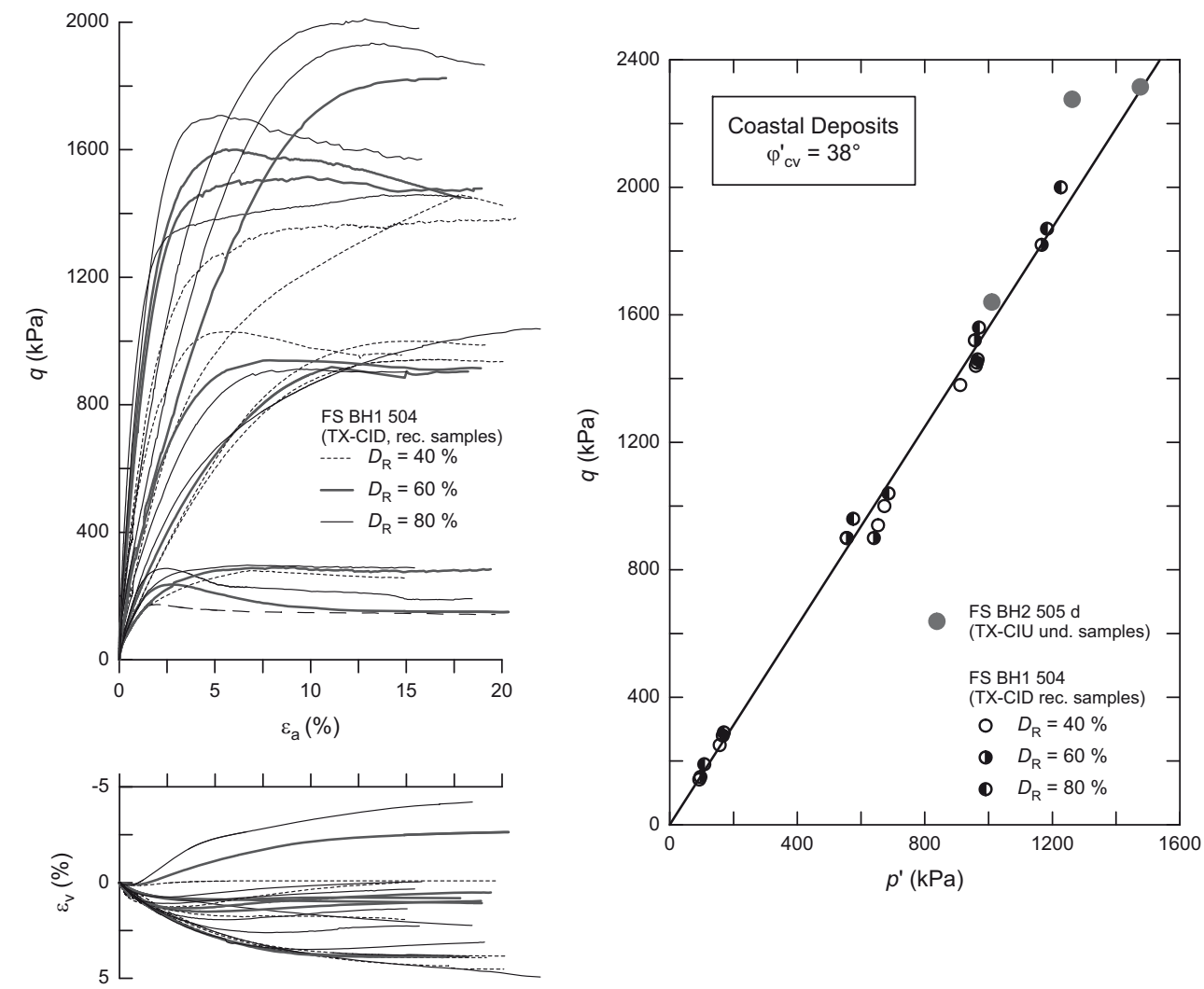

Fig. 4. Stress-strain curves and strength envelope for the coastal deposits. 
damping) for the three components of each recording. Some motion parameters are reported in Table 1 , where $a_{\max }$ is the maximum acceleration, $I_{A}$ is the Arias intensity, $T_{p}$ is the predominant period, $T_{m}$ is the mean period and $S D_{5-95}$ is the significant duration between $5 \%$ and $95 \%$ of the Arias intensity. The DHFS record appears more severe than the Arcelik record, being characterised by larger spectral accelerations and by a longer duration.

\subsection{Liquefaction}

Safety against liquefaction was checked using three different approaches:

a. conventional analyses that use the results of the in situ tests (Standard Penetration Tests, Cone Penetration Tests, measurement of shear wave velocity) to evaluate soil resistance, and peak ground acceleration to derive the seismic loading;

b. a decoupled approach, in which the seismic loading is evaluated from a site response analyses and the soil resistance is measured in the laboratory tests carried out on undisturbed samples;

c. a coupled approach entailing the use of an advanced constitutive model formulated in terms of effective stress, calibrated on the same laboratory tests used in the previous method.

A detailed description of all these analyses is beyond the scope of this paper, but approach (b) is particularly interesting because it involves undisturbed sampling of gravels and advanced laboratory testing, and can be described concisely as follows.

The undrained cyclic strength of the coastal deposits of the Sicily shore was determined experimentally through cyclic triaxial
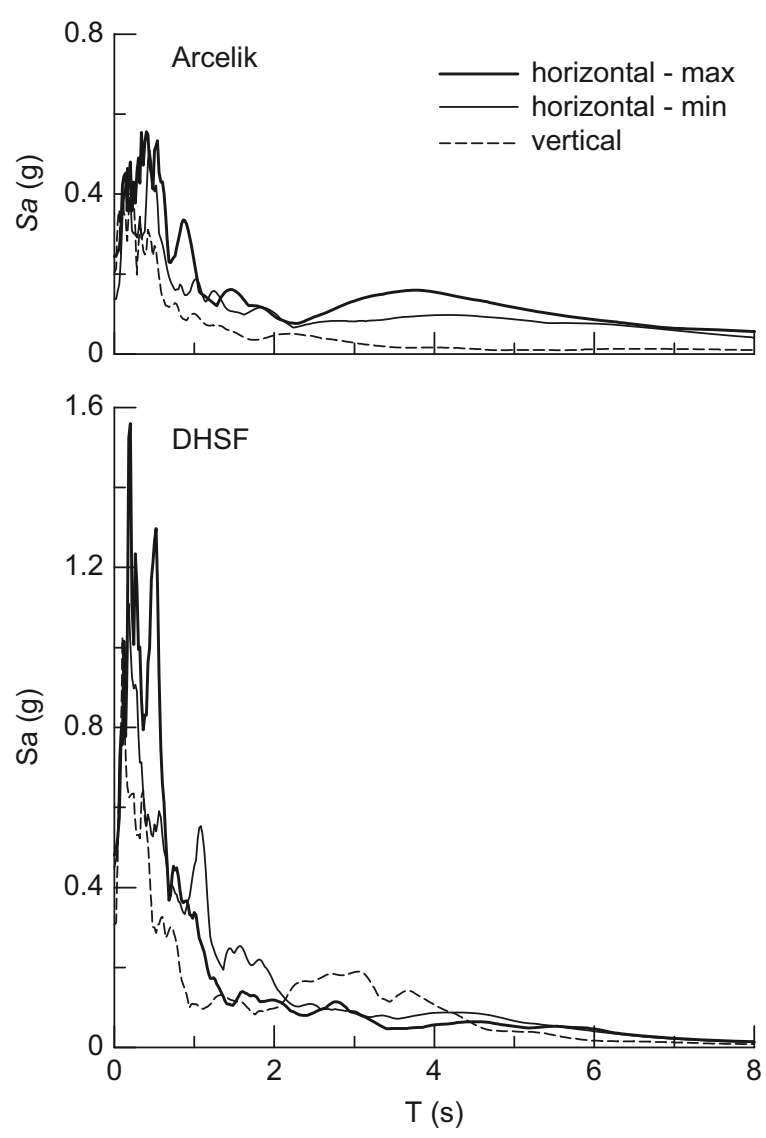

Fig. 5. Elastic response spectra for the two seismic recordings used in the interaction analyses. tests carried out on large diameter undisturbed samples retrieved with the freezing technique [7]. Fig. 6 shows the cyclic resistance ratio $C R R$ plotted as a function of the number of cycles. The values of $C R R$ from triaxial tests were converted into simple shear values using the correction factor $c_{\mathrm{r}}$ proposed by Castro [9]:

$c_{\mathrm{r}}=\frac{2\left(1+2 K_{0}\right)}{3 \sqrt{3}}$

where $K_{0}=0.47$ is the earth coefficient at rest, evaluated using the Jaky [10] relationship and accounting for ageing effects as suggested by Mesri and Castro [11].

In Table 2, the equivalent number of cycles $N_{\text {eq }}$ resulting from the study by Seed et al. [12] for a moment magnitude $M_{w}=7.1$ are compared with those derived from the study of Liu et al. [13], with reference to the mean plus or minus one standard deviation: in the liquefaction analyses, the values of $N_{\mathrm{eq}}$ by Liu et al. [13] were used since they correspond to a more severe earthquake loading.

The cyclic stress ratio CSR was obtained by one-dimensional site response analyses carried out in the frequency domain with an equivalent linear visco-elastic model [14]. The time histories of horizontal acceleration were de-convoluted (following the procedure by Roesset [15]) to the contact between the coastal deposits and the Messina gravels, and then re-propagated through the coastal deposits. At a given depth, the cyclic stress ratio is $\operatorname{CSR}=\tau_{\mathrm{eq}} / \sigma^{\prime}{ }_{v 0}$, where the equivalent shear stress $\tau_{\mathrm{eq}}$ is $65 \%$ of the

Table 1

Properties of the acceleration time histories used for the soil structure interaction.

\begin{tabular}{lllllll}
\hline Record & Component & $a_{\max }(\mathrm{g})$ & $I_{A}(\mathrm{~m} / \mathrm{s})$ & $S D_{5-95}(\mathrm{~s})$ & $T_{p}(\mathrm{~s})$ & $T_{m}(\mathrm{~s})$ \\
\hline \multirow{3}{*}{ Arcelik } & $H_{\max }$ & 0.244 & 0.55 & 7.43 & 0.40 & 0.70 \\
& $H_{\min }$ & 0.137 & 0.32 & 7.75 & 0.44 & 0.92 \\
& $V$ & 0.203 & 0.19 & 8.04 & 0.10 & 0.36 \\
\multirow{5}{*}{ DHSF } & $H_{\max }$ & 0.480 & 2.67 & 20.90 & 0.20 & 0.43 \\
& $H_{\min }$ & 0.450 & 2.39 & 29.96 & 0.18 & 0.46 \\
& $V$ & 0.307 & 1.95 & 25.54 & 0.10 & 0.40 \\
\hline
\end{tabular}

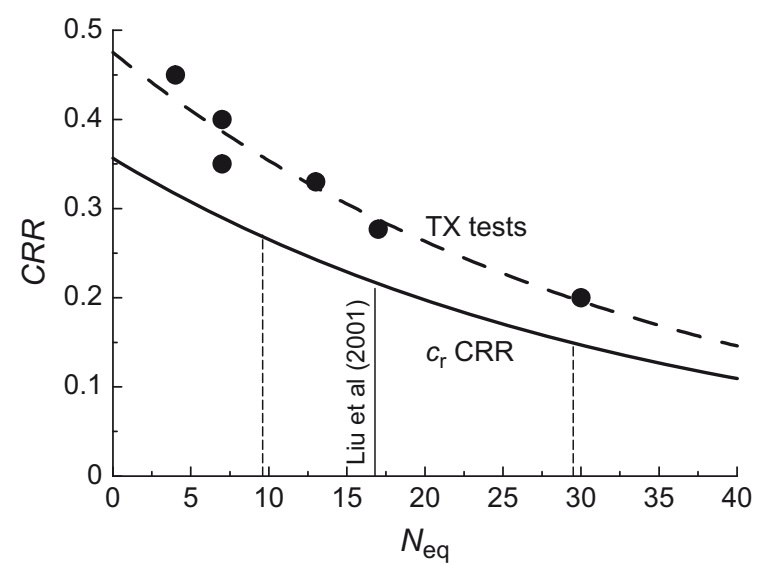

Fig. 6. Laboratory cyclic resistance ratio determined from cyclic undrained triaxial tests carried out on large-diameter undisturbed samples (Fioravante, et al., 2012 [7]).

Table 2

Values of the equivalent number of cycles for $M_{W}=7.1$.

\begin{tabular}{lcc}
\hline & $N_{\text {eq }}$ Liu et al. [13] & $N_{\text {eq }}$ Seed et al. [12] \\
\hline Mean $-\sigma$ & 9.6 & 5.0 \\
Mean & 16.8 & 10.5 \\
Mean $+\sigma$ & 29.5 & 15.5 \\
\hline
\end{tabular}


maximum shear stress computed in the site response analysis and $\sigma^{\prime}{ }_{\nu 0}$ is the corresponding vertical effective stress.

Fig. 7(a) shows the profiles of the maximum shear stress $\tau_{\max }$ resulting from the site response analyses and of the equivalent shear stress $\tau_{\text {eq }}=0.65 \tau_{\text {max }}$; Fig. 7 (b) compares the profiles of $C S R=\tau_{\text {eq }} / \sigma^{\prime}{ }_{v 0}$ with the profiles of $C R R$, obtained from Fig. 6 for the case of simple shear. The results from the two seismic inputs are very similar at depths larger than $40 \mathrm{~m}$; in the upper part of the deposit, and markedly in the first $20 \mathrm{~m}$, the DHSF record results in larger cyclic stress ratios. Specifically, between ground surface and a depth of about $17 \mathrm{~m}$, the cyclic stress ratio is larger than the most pessimistic cyclic resistance ratio, obtained from Fig. 6 for $N_{\text {eq }}$ corresponding to the mean plus one standard deviation values of Liu et al. [13]. This finding points to some possibility of liquefaction in free-field conditions between the ground surface and a depth of $17-20 \mathrm{~m}$, and it is broadly consistent with the results of procedure (a), that were somewhat more pessimistic, and with the results of the more refined liquefaction analyses (c), that accounted for the interaction between the soil skeleton and the pore fluid, relying on permeability measurements carried out in the coastal deposits. Therefore, it was deemed necessary to protect the upper foundation soils from the occurrence of liquefaction by an extensive jet grouting treatment that in the final design reaches a depth of $43 \mathrm{~m}$ below the foundation and of $33 \mathrm{~m}$ in the surrounding area.

\subsection{Analysis of the soil-structure interaction}

The seismic calculations for the bridge were carried out in two stages. In a first stage, the seismic input for the structural analysis

a

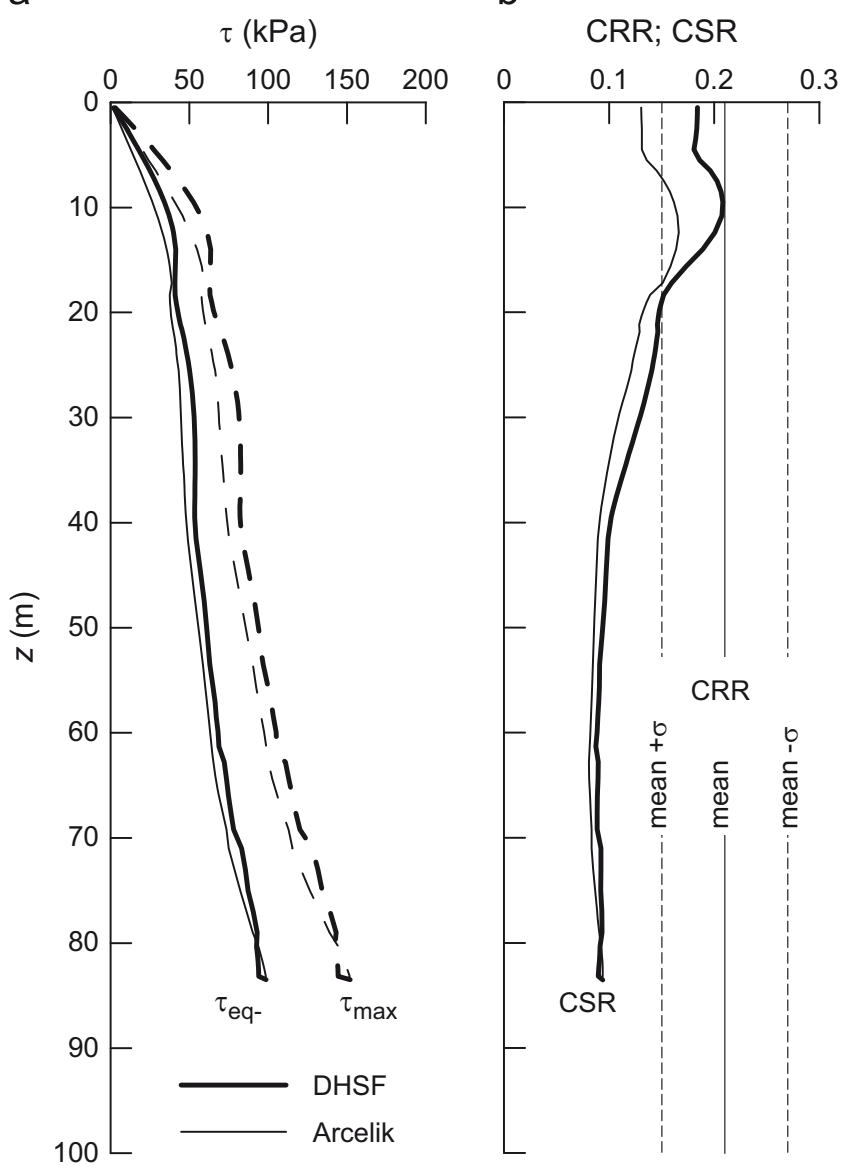

Fig. 7. Profiles of: (a) maximum and equivalent shear stresss, and (b) comparison between cyclic stress ratio and cyclic resistance ratio. was represented by a design elastic response spectrum. Spectral analyses were carried out, together with time-domain structural analyses, using a large number of acceleration time histories, in which the foundation deformability was represented through appropriate seismic impedance matrices, following the approach by Gazetas [16]. The resulting forces at the base of the bridge were applied incrementally to static three-dimensional soil-foundation models, to carry out a push-over analysis of the soil-foundation system. These analyses are not discussed in the present paper.

A subsequent verification stage included dynamic analyses of the soil-structure interaction, that considered explicitly the dynamic coupling of the soil and the structural behaviour. These analyses were carried out applying the two selected seismic records of Fig. 5 to numerical models that included the soil and the main structural elements. The dynamic analyses were carried out using the finite difference code FLAC.

It was found that the foundations on the Sicily and Calabria shores could be analysed separately, because the natural periods for the cable and deck modes are much larger (10-30 s) than those associated with the dynamic response of the towers (2.5-3 s) and of the subsoil (1-2 s), making the dynamic interaction between the two shores negligible.

Simplified structural models for the towers were included in the finite difference calculation grids. These structural models include a representation of the restraint provided by the suspension system through simple linear elastic springs that, because of the very large cable natural period, connect the top of each tower to a fixed point (Fig. 8); for the same reason, it could be assumed that the anchor block elements are loaded by a constant force, representing the maximum cable force evaluated in the spectral analyses.

The calculations were carried out in plane strain conditions. This is a very significant simplification of the actual problem, that has several consequences, as listed below:

a. Different numerical models were needed to evaluate the bridge response in the longitudinal and transverse directions. Specifically, two large longitudinal models were developed for each shore including the tower, the terminal structure and the anchor block. The dimensions of the longitudinal calculation domain adopted for the Sicily shore can be appreciated from Fig. 2, while a portion of the finite difference grid is shown in Fig. 8(a). For the transverse direction, a different numerical model was needed for each foundation element, for a total of six transverse domains. As an example, Fig. 8(b) shows the transverse finite difference grid for the Sicily tower.

b. It was necessary to convert three-dimensional structural elements into their corresponding plane strain representation. This was done by defining for each model an equivalent length in a direction normal to the analysis plane, that was used to scale the weight and the stiffness of the structural elements. The equivalent length was defined as the length producing the same displacements and rotations in simple static two- and three-dimensional computations in which the soil was regarded as a linearly elastic continuum. The equivalent lengths for each foundation element are listed in Table 3.

c. Longitudinal and transverse models yielded horizontal and vertical displacements of the foundation elements, and rotations in the longitudinal and transverse planes: the adopted procedure intrinsically neglects any rotation in a horizontal plane.

As a general result, the overall deformation pattern resulting from the dynamic analyses were consistent with that obtained in the three-dimensional push-over analyses, and this dissipated any concern that the plane strain assumption could hide some particular deformation mechanism. 



Fig. 8. (a) A portion of the longitudinal finite difference grid for the Sicily tower, and (b) transverse grid.

Table 3

Equivalent lengths for the conversion of weight and stiffness to plane strain conditions.

\begin{tabular}{lll}
\hline Foundation element & Longitudinal model $(\mathrm{m})$ & Transverse model $(\mathrm{m})$ \\
\hline Sicily anchor block & 184 & 119 \\
Sicily tower & 147 & 66 \\
Calabria tower & 129 & 64 \\
Calabria anchor block & 184 & 139 \\
\hline
\end{tabular}

\subsubsection{Structural elements}

Simplified structural models for the towers were developed with the aim of reproducing their first modes of vibration; each of them consists of a series of beams with different mass density and bending stiffness in the analysis plane. The top of each tower model is connected to a horizontal elastic spring with a stiffness of $556 \mathrm{MN} / \mathrm{m}$ and $268 \mathrm{MN} / \mathrm{m}$ in the longitudinal and transverse directions, respectively, representing the restraining effect of the suspension system. A FLAC local damping equivalent to a viscous damping ratio $D=5 \%$ was introduced for these structural elements. Local damping in FLAC operates by adding or subtracting an equivalent amount of mass from structural nodes at certain times during a cycle of oscillation, so that an overall conservation of mass is ensured.

The masses of the simplified structural models produce a gravitational load (1.45 GN in the longitudinal model, $2.02 \mathrm{GN}$ in the transverse model) that is smaller than the actual vertical load transmitted by the tower to the foundations (amounting to about 2.6 GN); therefore, additional vertical forces were applied on the foundation elements in order to reproduce the initial stress state in the soil.

This simplified structural models, including the spring constants, were developed using a structural identification procedure and were validated by comparing the plane strain dynamic response evaluated using FLAC with the corresponding response of the full three-dimensional tower models studied with the software ADINA. As an example, Fig. 9 illustrates the dynamic response of the simplified tower model used for the longitudinal finite difference grid of the Sicily shore. Specifically, Fig. 9 (a) presents the tower response to a frequency sweep, computed at nodes N18 and N20 of Fig. 8(a) and expressed in terms of
Fourier displacement amplitudes $A$. The first peak identifies the first natural frequency of the simplified tower model in the longitudinal direction, that is practically the same as that of the three-dimensional model, equal to $0.39 \mathrm{~Hz}$. Fig. 9(b) compares the first modal shape of the simplified tower model, obtained from the finite-difference results at a frequency of $0.39 \mathrm{~Hz}$, with that computed for the three-dimensional model.

The reinforced concrete foundation elements and the anchor blocks were modelled as linear elastic materials with a Young's modulus of $40 \mathrm{GPa}$ and a Poisson's ratio of 0.15 . The unit weight of these structural elements was scaled to obtain a self-weight of the equivalent plane-strain foundation equal to the self-weight of the actual three-dimensional foundation. The reinforced concrete box beam that connects the two footings of the each tower was included in the transverse models as a beam element with axial and bending stiffness $E A=95 \mathrm{GN} / \mathrm{m}$, and $E I=1900 \mathrm{GN} / \mathrm{m}$. The anchor blocks were subjected to constant cable forces, equal to $3.9 \mathrm{GN}$ acting with an upward inclination of $15^{\circ}$.

\subsubsection{Soil behaviour}

In the dynamic analyses, the cyclic soil behaviour was described using the hysteretic damping model available in FLAC. Basically, the model consists in an extension to general strain conditions of the one-dimensional non-linear models that make use of the Masing [17] rules to produce hysteresis loops [18,19]. The model requires the small-strain shear modulus $G_{0}$ and a modulus decay curve that describes the reduction of the secant shear modulus with the shear strain amplitude. The small-strain shear modulus was calibrated using the results of the cross-hole tests, and was described as a function of the mean effective stress:

$\frac{G_{0}}{p_{\text {ref }}}=K_{\mathrm{G}}\left(\frac{p^{\prime}+B}{p_{\text {ref }}}\right)^{n}$

where $p^{\prime}$ is the mean effective stress, $p_{\text {ref }}=100 \mathrm{kPa}$ is a reference pressure, and $K_{\mathrm{G}}, B$ and $n$ were obtained by best fitting the crosshole test results. Both the coastal deposits and the Messina gravels were subdivided in sub-layers to better reproduce the variation of soil stiffness with depth (see Table 4).

The adopted modulus decay for the Messina gravels and the coastal deposits was based on experimental results obtained by Tanaka et al. [20] for reconstituted gravelly soils with a gravel 

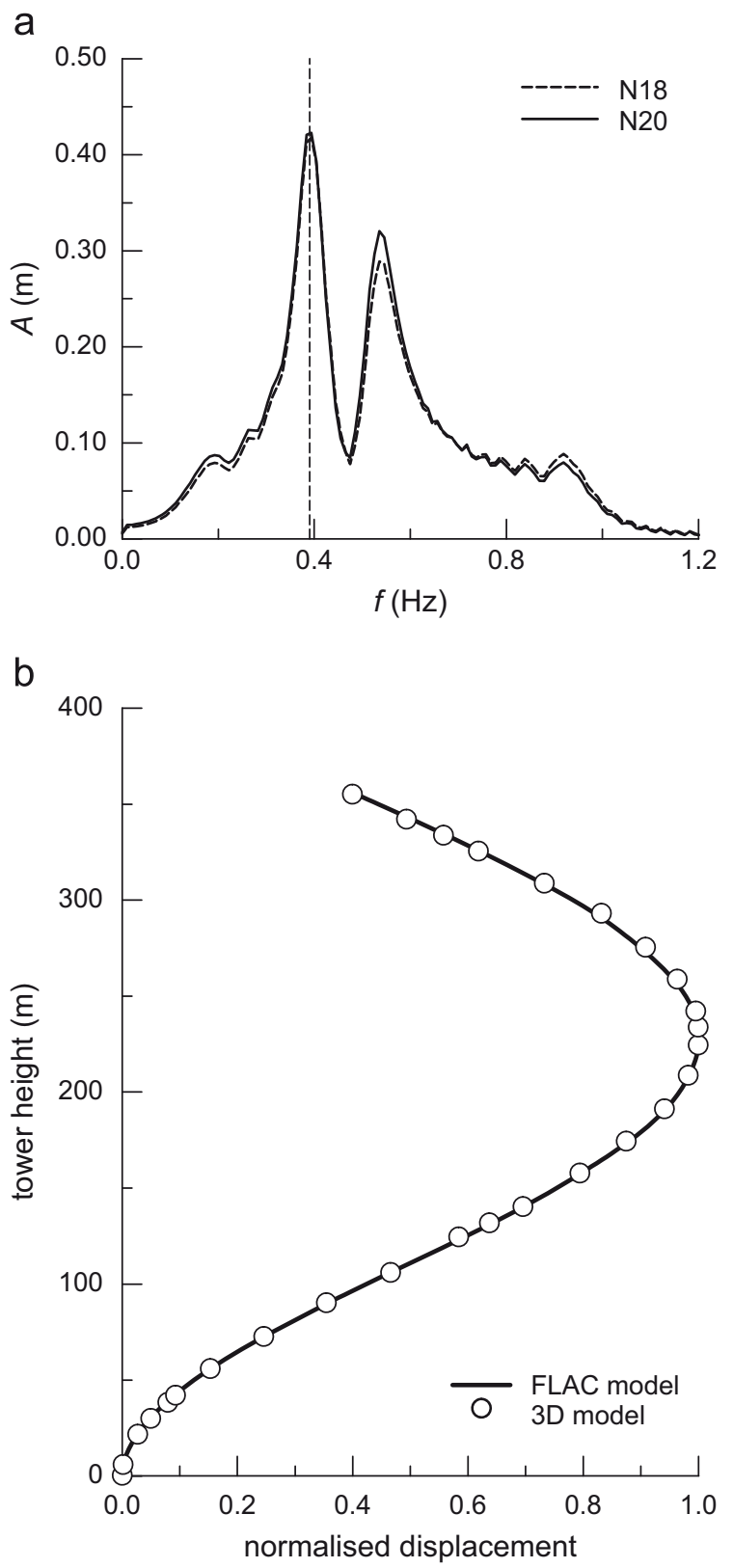

Fig. 9. Sicily shore-longitudinal analysis: dynamic response of the simplified tower model: (a) Fourier response to a frequency sweep, and (b) first modal shape.

content of $50 \%$ under a confining effective stress of $200 \mathrm{kPa}$. This modulus decay curve was approximated using the built-in FLAC model for the normalised secant modulus reduction:

$\frac{G}{G_{0}}=y_{0}+\frac{a}{1+\exp \left[-\left(\log _{10} \gamma-x_{0}\right) / b\right]}$

with the values of $a, b, x_{0}$ and $y_{0}$ reported in Table 5 .

Fig. 10(a) compares the modulus decay curve No. 1, predicted using the parameters of Table 5, with the experimental data reported by Tanaka et al. [20] and with a similar modulus decay curve provided by Seed and Idriss [21] for coarse-grained soils. This figure also shows the corresponding equivalent damping ratio $D$ plotted as a function of the shear strain amplitude $\gamma$. In the hysteretic soil model the equivalent damping ratio is a response of the constitutive model and cannot be further calibrated. Although for $\gamma>0.01 \%$ the equivalent damping ratio provided by the hysteretic model is somewhat larger than the experimental one, it should be remarked that the present numerical analyses use a truly non-linear soil model, and are carried out in the time domain. Therefore, the values of $D$ are only activated in the time instants when the strains are largest. Preliminary one-dimensional free-field comparisons between the predictions of the hysteretic model and those of an equivalent linear calculation with a viscoelastic model [14] yielded a reasonable agreement and showed that values of the shear strain larger than $0.01 \%$ are only locally and instantaneously attained for the seismic input used in the present simulations. The modulus decay curve No.1 was adopted

Table 4

Soil parameters ( $\gamma$ is the unit weight; $\varphi^{\prime}$ is the angle of shearing resistance; $K_{0}$ is the earth coefficient at rest, $\nu$ is the Poisson ratio, $K_{\mathrm{G}}, B$ and $n$ are defined in Eq. (3)).

\begin{tabular}{llllllllll}
\hline Soil layer & $\begin{array}{l}\text { Depth } \\
(\mathrm{m})\end{array}$ & $\begin{array}{l}\gamma(\mathrm{kN} / \\
\left.\mathrm{m}^{3}\right)\end{array}$ & $\begin{array}{l}\varphi^{\prime} \\
\left.{ }^{\circ}\right)\end{array}$ & $K_{0}$ & $\nu$ & $K_{\mathrm{G}}$ & $\begin{array}{l}B \\
(\mathrm{kPa})\end{array}$ & $n$ \\
\hline Coastal deposits & $<30$ & 20 & 44 & 0.47 & 0.2 & 800 & 15 & 0.50 \\
Coastal deposits & $>30$ & 20 & 42 & 0.50 & 0.2 & 800 & 15 & 0.50 \\
Messina gravel/1 & $<30$ & 20 & 44 & 0.50 & 0.2 & 890 & 60 & 0.86 \\
Messina gravel/1 & $30-90$ & 20 & 42 & 0.50 & 0.2 & 890 & 60 & 0.86 \\
Messina gravel/2 & $90-120$ & 20 & 42 & 0.50 & 0.2 & 24200 & - & 0 \\
Messina gravel/3 & $>120$ & 20 & 42 & 0.50 & 0.2 & 24200 & - & 0 \\
\hline
\end{tabular}

Table 5

Constitutive parameters used for the hysteretic soil model.

\begin{tabular}{lllll}
\hline Curve no. & $a$ & $b$ & $x_{0}$ & $y_{0}$ \\
\hline 1 & 0.976 & -0.439 & -1.285 & 0.032 \\
2 & 0.990 & -1.100 & -0.100 & 0.050 \\
\hline
\end{tabular}

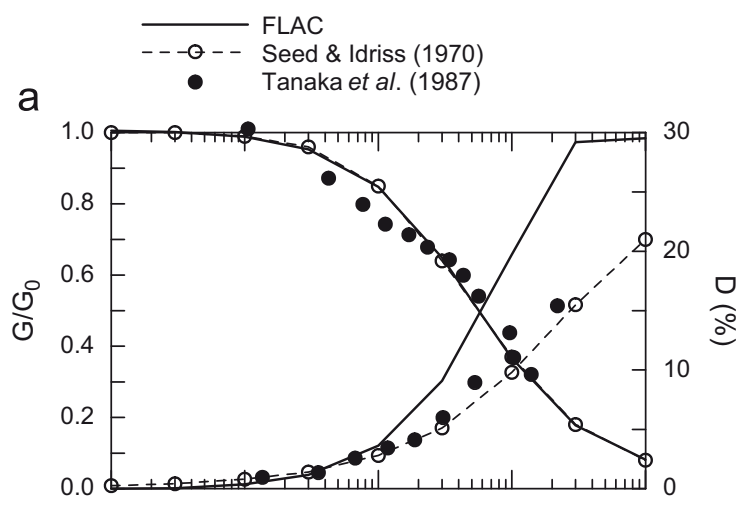

b

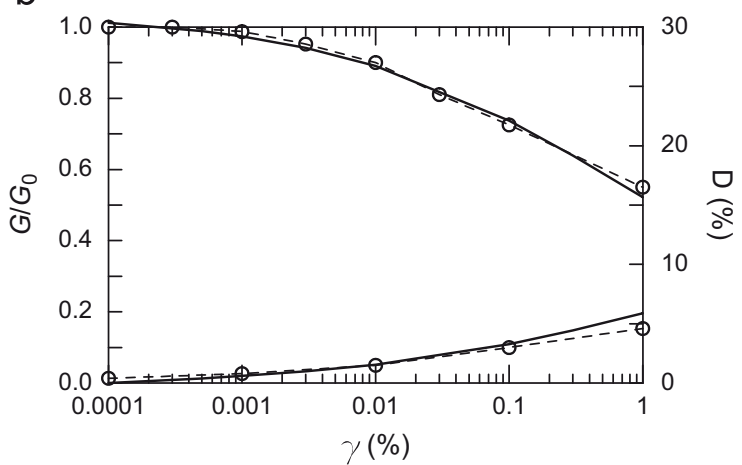

Fig. 10. Calibration of the hysteretic soil model: (a) Coastal deposits, Messina gravels/ 1 and lateral jet-grouted soil; (b) Messina gravels/2/3 and jet-grouted soil below the tower foundation. 
for the coastal deposits, the Messina gravels/1, and the lateral jetgrouted soil.

Fig. 10(b) shows the modulus decay curve No. 2 adopted for the deeper soil strata (Messina gravel/2 and/3) and for the extensive jet-grouting treatment below the tower foundation, together with the damping curve. In this case only a limited modulus decay was assumed, corresponding to a $10 \%$ modulus reduction for a shear strain of $0.01 \%$.

In the analyses, the hysteretic model was used to update at each calculation step the (tangent) shear modulus of an elastic-perfectly plastic soil model with a Mohr-Coulomb failure criterion. A nonassociated flow rule was used, with a dilatancy angle set to zero. Coupling the hysteretic behaviour with a perfectly plastic model has the consequence that plastic strains associated to full strength mobilization can provide some additional energy dissipation.

At very small strains, the hysteretic model provides no damping. Therefore an additional viscous Rayleigh damping ( $D=4 \%$ at a central frequency of $4 \mathrm{~Hz}$ ) was used in the computations, in order to provide some energy dissipation also at small strains. Preliminary parametric analyses showed that this small viscous damping does not alter significantly the results, but helps in smoothing out some high-frequency response that is an inevitable consequence of a fully explicit time-integration scheme [22].

The behaviour of the jet-grouted soil was described through a homogenisation procedure, based on the areal treatment ratio, that is equal to $100 \%$ below the tower foundations and to $42 \%$ laterally. The design unconfined compression strength of the jetgrouted columns is $\sigma_{c}=6 \mathrm{MPa}$; this unconfined strength was simulated evaluating the corresponding cohesion intercept of a Mohr-Coulomb failure criterion having a friction angle of $35^{\circ}$, that is a very low estimate of the constant volume friction angle. The shear stiffness of the jet-grouted soil was derived assuming a ratio of the Young's modulus to the unconfined strength $E / \sigma_{c}=500$, selected according to experimental results published by Croce et al. [23]. The corresponding mechanical properties of the jetgrouted soil are reported in Table 6.

\subsubsection{Analysis procedure}

For each plane strain model, the first step consisted in the calculation of the in situ stress; this was accomplished by applying to each grid zone the overburden vertical stress, $\sigma_{\nu 0}$, the pore water pressure, $u$, and the horizontal effective stress, $\sigma_{h 0}^{\prime}=K_{0}\left(\sigma_{\nu 0}-u\right)$, and stepping for equilibrium. In a subsequent phase, the construction of the bridge was simulated by activating the structural elements that represent the foundation, the jet-grouted soil and the superstructure, and by applying the additional vertical forces transmitted to the foundation (as discussed in Section 3.3.1). To account for soil non linearity, these static steps were carried out modelling the soil as an elastic-perfectly plastic material with an elastic stiffness equal to $30 \%$ of the small-strain shear stiffness of Table 5 ; the horizontal and vertical displacements at the grid bottom and the horizontal displacement at the grid sides were restrained.

The seismic stages of the analyses were performed applying horizontal and vertical acceleration time histories to the bottom boundary of the grid, that accounted for the finite stiffness of the deposits encountered at larger depths. This procedure is illustrated in Fig. 11 for the specific case of the Sicily shore. The selected seismic records of Table 1 refer to an ideally stiff outcrop.

\section{Table 6}

Mechanical parameters used for the jet-grouted soil.

\begin{tabular}{lllllc}
\hline Location & $\gamma\left(\mathrm{kN} / \mathrm{m}^{3}\right)$ & $c^{\prime}(\mathrm{kPa})$ & $\varphi^{\prime}\left({ }^{\circ}\right)$ & $\nu$ & $G_{0}(\mathrm{MPa})$ \\
\hline Below the foundations & 22 & 1560 & 35 & 0.2 & 1250 \\
Lateral & 22 & 655 & 35 & 0.2 & 525 \\
\hline
\end{tabular}

Following Joyner and Chen [22], these records were converted into equivalent stress time histories at a depth of $445 \mathrm{~m}$, corresponding to the top of the Pezzo Conglomerate, which has estimated shear and compression wave velocities of 1700 and $2700 \mathrm{~m} / \mathrm{s}$, respectively. The upward propagating wave in the Pezzo Conglomerate is equal to half the outcrop motion. For the horizontal and vertical components of the motion it is:

$a_{\mathrm{bh}}(t)=0.5 a_{h}(t)$

$a_{\mathrm{bv}}(t)=0.5 a_{v}(t)$

where $a_{h}$ and $a_{v}$ are the recorded outcrop horizontal and vertical accelerations, and $a_{\mathrm{bh}}$ and $a_{\mathrm{bv}}$ are the corresponding upward propagating acceleration waves in the bedrock.

The above acceleration time histories can be integrated to evaluate the corresponding particle velocities $v_{\text {bh }}(t)$ and $v_{\text {bv }}(t)$; the upward propagating shear and normal stress waves are:

$\tau(t)=2 \rho V_{s} v_{\mathrm{bh}}(t)$

$\sigma(t)=2 \rho V_{p} v_{\mathrm{bv}}(t)$

where $\rho$ is the mass density, and $V_{s}$ and $V_{p}$ are the velocities of the shear and compression waves in the Pezzo conglomerate. The computed stress time histories were applied at the bottom of a one-dimensional column $445 \mathrm{~m}$ long (Fig. 11) together with quiet boundaries, which consist of dashpots attached independently to the same boundary in the tangential and normal directions. The dashpots provide viscous tangential and normal tractions [24]:

$\tau_{D}(t)=-\rho V_{s} v_{h}(t)$

$\sigma_{D}(t)=-\rho V_{p} v_{v}(t)$

where $v_{h}$ and $v_{v}$ are the horizontal and vertical velocities at the bottom boundary. During the calculation, the incident stress waves combine with the dashpot reactions to give resultant boundary stress waves:

$\tau_{B}(t)=\rho V_{s}\left[2 v_{b h}(t)-v_{h}(t)\right]$
$\sigma_{B}(t)=\rho V_{p}\left[2 v_{b v}(t)-v_{v}(t)\right]$

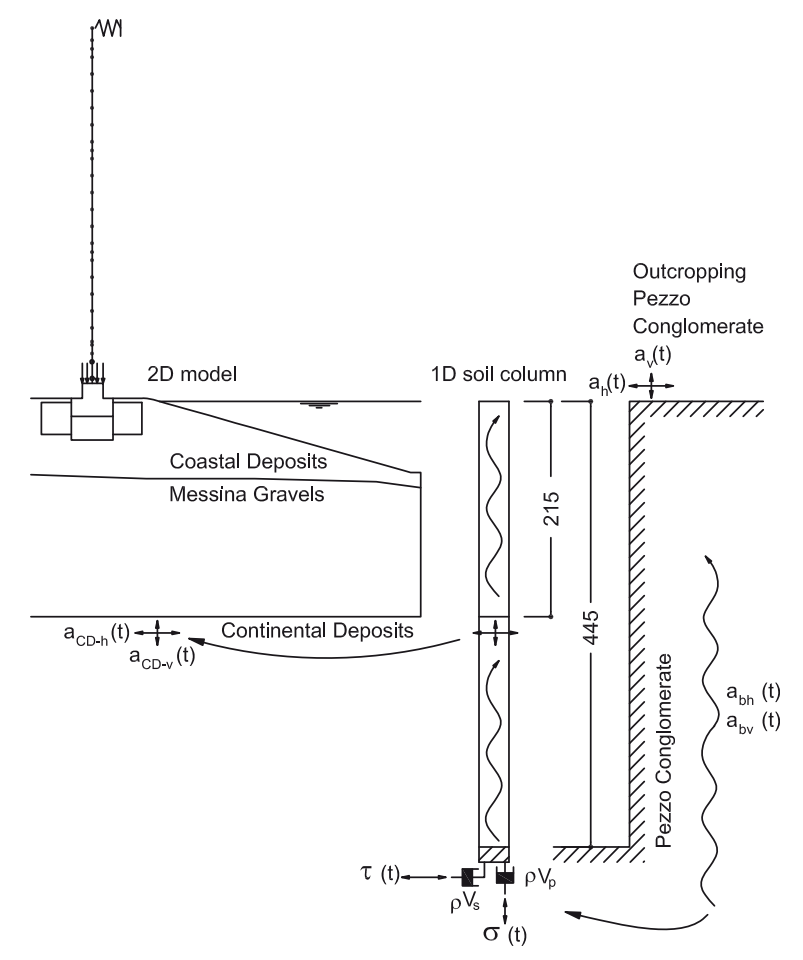

Fig. 11. Schematic representation of the deconvolution procedure for the Sicily shore. 
that are coincident with the results of Joyner and Chen [22]. In the finite difference code FLAC, the properties of the dashpots that simulate the quiet boundaries are linked to the properties of the parent material. Therefore, in order to have the correct dashpot coefficients in Eq. (7) it was necessary to introduce a thin layer of Pezzo Conglomerate at the bottom of the one-dimensional column of Fig. 11.

The soil column was used to perform a one-dimensional site response FLAC analysis from which the horizontal and vertical acceleration time histories $\left(a_{\mathrm{CD}-h}(t)\right.$ and $a_{\mathrm{CD}-v}(t)$ in Fig. 11) at the contact between the Messina gravels and the Continental Deposits could be extracted. These acceleration time histories intrinsically account for the deformability of the deposits found at larger depths and were applied directly to the bottom boundary of the two-dimensional grid.

During the seismic stages, the constraints on the lateral sides were removed and the FLAC 'free-field' boundary conditions were applied, in which the lateral boundaries of the main grid are coupled to one-dimensional columns through Lysmer and Kuhlemeyer [24] viscous dashpots. Along these free-field columns a one-dimensional calculation is carried out in parallel with the main grid calculation. In this way, if the main grid motion differs from that of the free-field, for instance due to waves radiating away from the foundation elements, then the dashpots are activated to inhibit wave reflection.

Each seismic record was applied to the base of the twodimensional models using the four combinations summarised in Table 7, where $H_{\max }, H_{\min }$ and $V$ indicate the acceleration components listed in Table 1. A positive sign for the horizontal acceleration indicates that this is positive Southwards and Eastwards, in the longitudinal and transverse section, respectively.

The recorded accelerations were filtered using a Butterworth low-pass filter at $15 \mathrm{~Hz}$, for compatibility with the dimensions of the grid zones, and a quadratic baseline correction was applied before they were converted into stress time histories. To reduce the computational time for earthquake DHSF, that has a total duration of about $82 \mathrm{~s}$, the 2D numerical analyses considered only the accelerations between $15 \mathrm{~s}$ and $70 \mathrm{~s}$, that contain all the acceleration values of some significance.

The calculations were carried out in terms of effective stresses; as the previous liquefaction analyses had indicated negligible excess pore water pressure below the jet-grouted areas, any dynamic increase in pore-water pressure was neglected in the present analyses. The time increment used in the explicit time integration scheme was $\Delta t=5 \times 10^{-6} \mathrm{~s}$ in all models, with the exception of the transverse model of the Sicily tower, where the time interval was $\Delta t=2.5 \times 10^{-6} \mathrm{~s}$.

\section{Discussion of results}

Figs. 12 and 13 show the 5\%-damped elastic response spectra of the horizontal acceleration time histories computed for the DHSF record combination No. 3 at selected points of the Sicily models. Fig. 12 compares the motion computed at the grid bottom $\left(a_{\mathrm{CD}-h}\right.$ in Fig. 11) with the site response evaluated in the free-field at the ground surface and at a depth of $20 \mathrm{~m}$, that corresponds to the

Table 7

Seismic input combinations used in dynamic stages of 2D numerical analyses.

\begin{tabular}{llll}
\hline Combination & Longitudinal & Transverse & Vertical \\
\hline 1 & $H_{\max }$ & $H_{\min }$ & $V$ \\
2 & $-H_{\max }$ & $-H_{\min }$ & $V$ \\
3 & $H_{\min }$ & $H_{\max }$ & $V$ \\
4 & $-H_{\min }$ & $-H_{\max }$ & $V$ \\
\hline
\end{tabular}

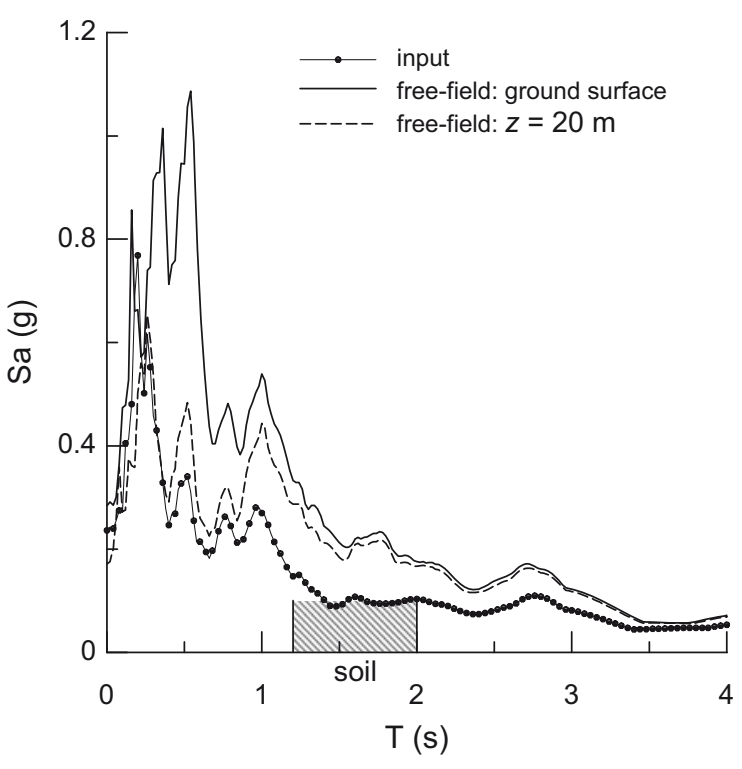

Fig. 12. Elastic response spectra computed using the DHSF record, combination åNo. 3: free-field response.

bottom of the tower foundation. The hatched interval indicates the range of fundamental periods for the foundation soil, taking into account the progressive modulus decay.

At the ground surface, significant amplifications are computed for periods ranging between 0.3 and $3.5 \mathrm{~s}$, that encompass the fundamental periods of the soil deposit; the maximum ratio between the spectral ordinates, equal to about 3.9 , is obtained at a period of $0.6 \mathrm{~s}$. At a depth of $20 \mathrm{~m}$ the amplification at low periods is much less significant and the maximum spectral acceleration ratio is of 2.3 at $T=1.8 \mathrm{~s}$, well within the range of the fundamental periods of the soil deposits.

Fig. 13(a) and (b) show the response spectra of the horizontal acceleration time histories computed at the tower base and at the anchor block in the transverse and longitudinal directions. The figures also show the range of the natural periods of the anchor block and the tower foundations, regarded as rigid bodies immersed into an equivalent elastic continuum; within this interval, the larger periods represent the combined response to translation and rocking. The first natural period of the tower is also indicated.

The response spectra computed in the transverse direction (Fig. 13(a)) at the locations of the tower and the anchor block are not too dissimilar from the free-field response at $z=20 \mathrm{~m}$. Specifically, the transverse tower motion differs from the free-field motion only in the range of 0.15 to $0.6 \mathrm{~s}$ : the mass and stiffness of the tower foundations produce an increase in the periods corresponding to the maximum amplification. The anchor block produces a further increase of the predominant period, together with a larger amplification. This effect is associated to the combination of translation and rocking of the anchor block, that has a larger natural period of the translation alone. As rocking is substantially limited by the twin-legs arrangement of the tower's structure (see Fig. 8), the amplification at the larger period is significant only for the anchor block. Conversely, in the longitudinal plane the tower foundation has a lower rotational stiffness and the contribution of rocking can be significant; accordingly, Fig. 13(b) shows that in the longitudinal direction there is a substantial long-period amplification at the tower base too. It should be observed that in the longitudinal direction the ground surface is rather irregular: the anchor block is immersed in a small hill, while the tower foundation is located in the vicinity of a submerged slope. Therefore, the 
a

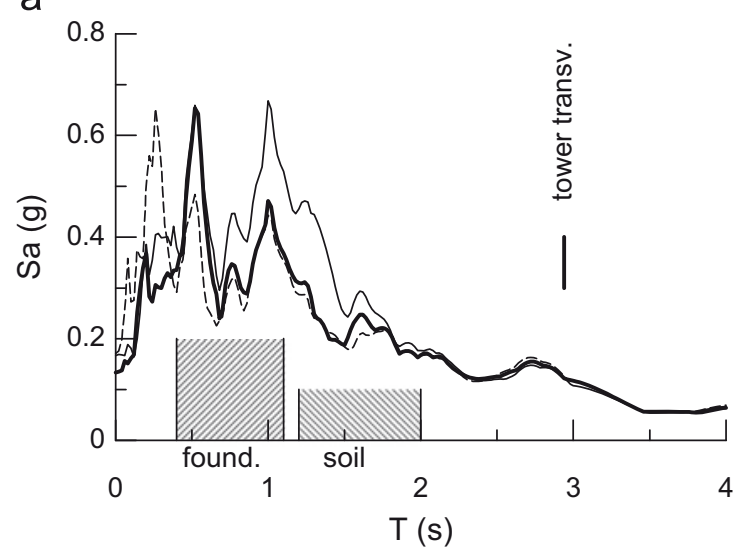

b

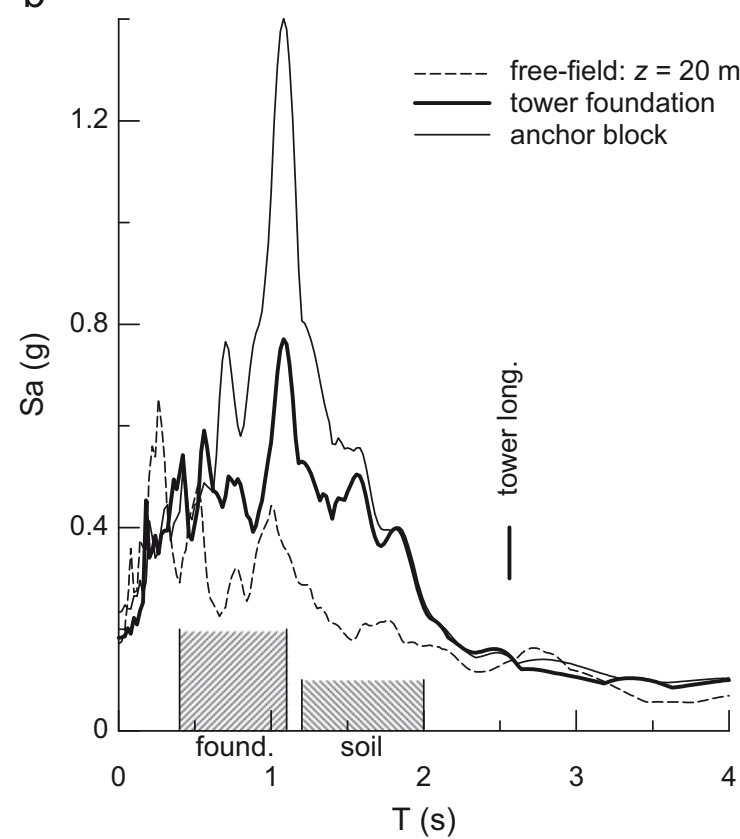

Fig. 13. Elastic response spectra computed using the DHSF record, combination åNo. 3: (a) tower and block response in the transverse direction; (b) tower and block response in the longitudinal direction.

largest spectral accelerations of Fig. 13(b) can be partly due to focalisation of seismic waves.

It is interesting to note that the vibration period associated to the first mode of the superstructure, marked in Fig. 13, has almost no effect on the spectral response of the tower foundation: soil motion resulting from soil-structure interaction is affected more by the behaviour of the immersed foundation elements than by the dynamic response of the superstructure.

For the DSFH record combination No. 3, Fig. 14 shows the time histories of the horizontal displacements of the tower foundations and of the anchor block, together with the time history of the rotations at the tower base; the horizontal acceleration time history applied to the bottom mesh boundary is also shown for comparison. These plots shows that permanent deformation is generated mainly during the final phase of the strong motion between about $20 \mathrm{~s}$ to $30 \mathrm{~s}$. Inspection of the stress state in the soil during this time interval reveals that the soil strength is attained only locally in the soil interacting with the anchor block and the tower foundation, and there is no evidence of any global plastic mechanism. For instance, for the longitudinal model in the vicinity of the Sicily anchor block, Fig. 15 shows the lines of equal shear

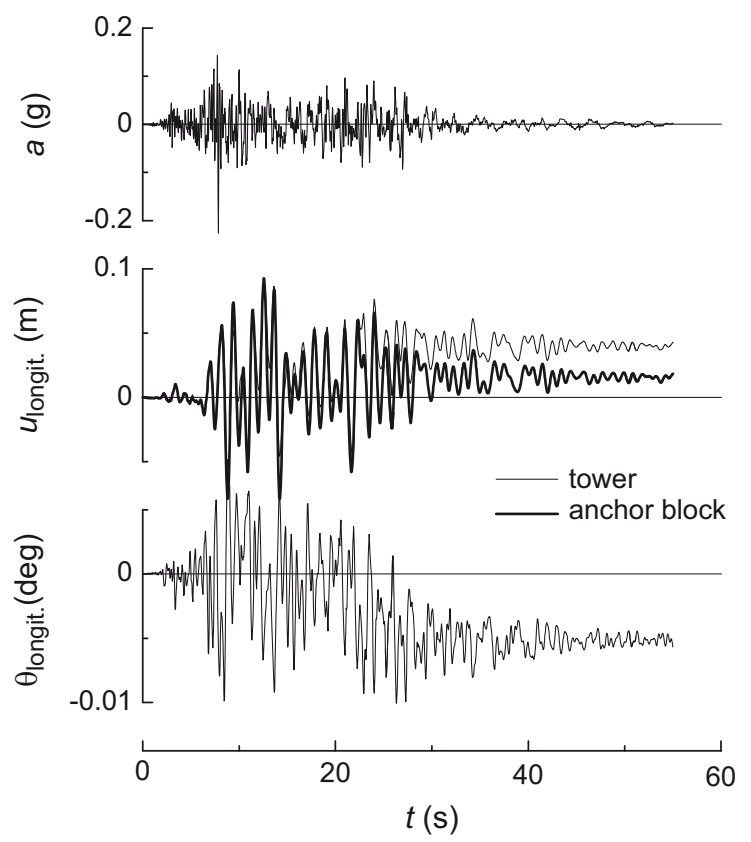

Fig. 14. Computed displacements and rotations for the Sicily foundations: DSFH record, combination No. 3: (a) base acceleration; (b) longitudinal displacements for the tower and the anchor block; (c) rotation at the tower foundation.

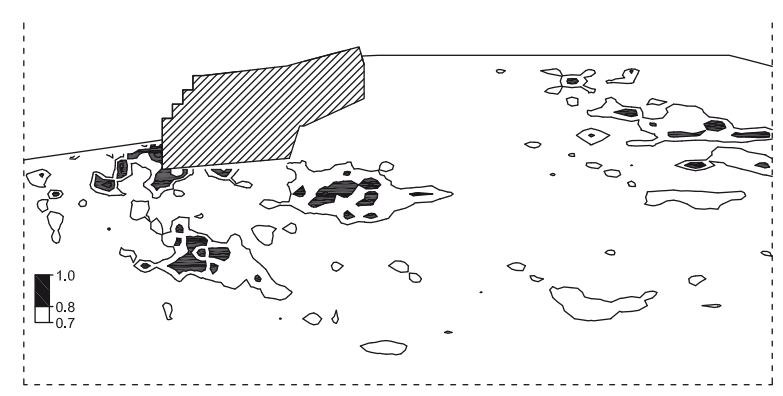

Fig. 15. Contours of mobilised shear strength $\tau / \tau_{\max }$ at $t=27.8 \mathrm{~s}$ for the Sicily anchor block analysed in the longitudinal direction (DHS record combination No. 3 ).

strength ratio $\tau / \tau_{f}$ computed at $t=27.8 \mathrm{~s}$, where $\tau$ is the maximum shear stress and $\tau_{f}$ is the corresponding shear stress at failure. Zones with ratios $\tau / \tau_{\max }$ larger than 0.8 , indicating a significant strength mobilization, are visible only locally below the block foundation. However, Fig. 16 shows that during the simulation, at some time or another the shear strength is fully mobilised in a significant portion of the grid zones close to the ground surface and to the foundation elements. Therefore, it can be concluded that the computed permanent deformations are the combined effect of both the pre-failure permanent strains predicted by the hysteretic soil model and the instantaneous mobilization of the shear strength in the foundation soil.

The permanent deformations computed in the analyses for the different foundation elements are summarised in the bar charts of Fig. 17, with reference to the maximum horizontal displacements and rotations computed in the longitudinal plane using for each seismic record the four combinations of Table 7. All these deformations are directed towards the centre of the Strait. As a general result, the computed horizontal displacements are smaller than $50 \mathrm{~mm}$ while the rotations are less than $0.015^{\circ}$. In most cases the DHSF record produces deformations larger than the Arcelik record. The horizontal displacements are more significant for the Sicily foundation elements, while the maximum rotation is computed for the Calabria tower: this is due to the local soil profile that 


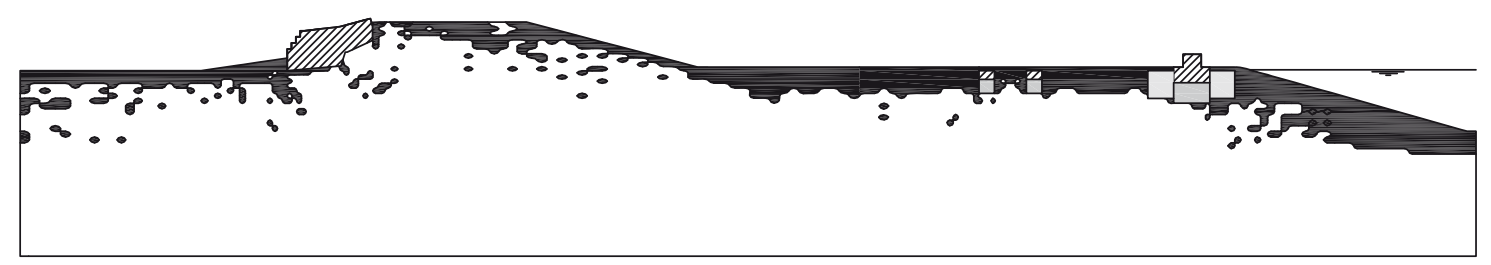

Fig. 16. Grid zones in which the shear strength was fully mobilised during the earthquake (DHS record combination No. 3).

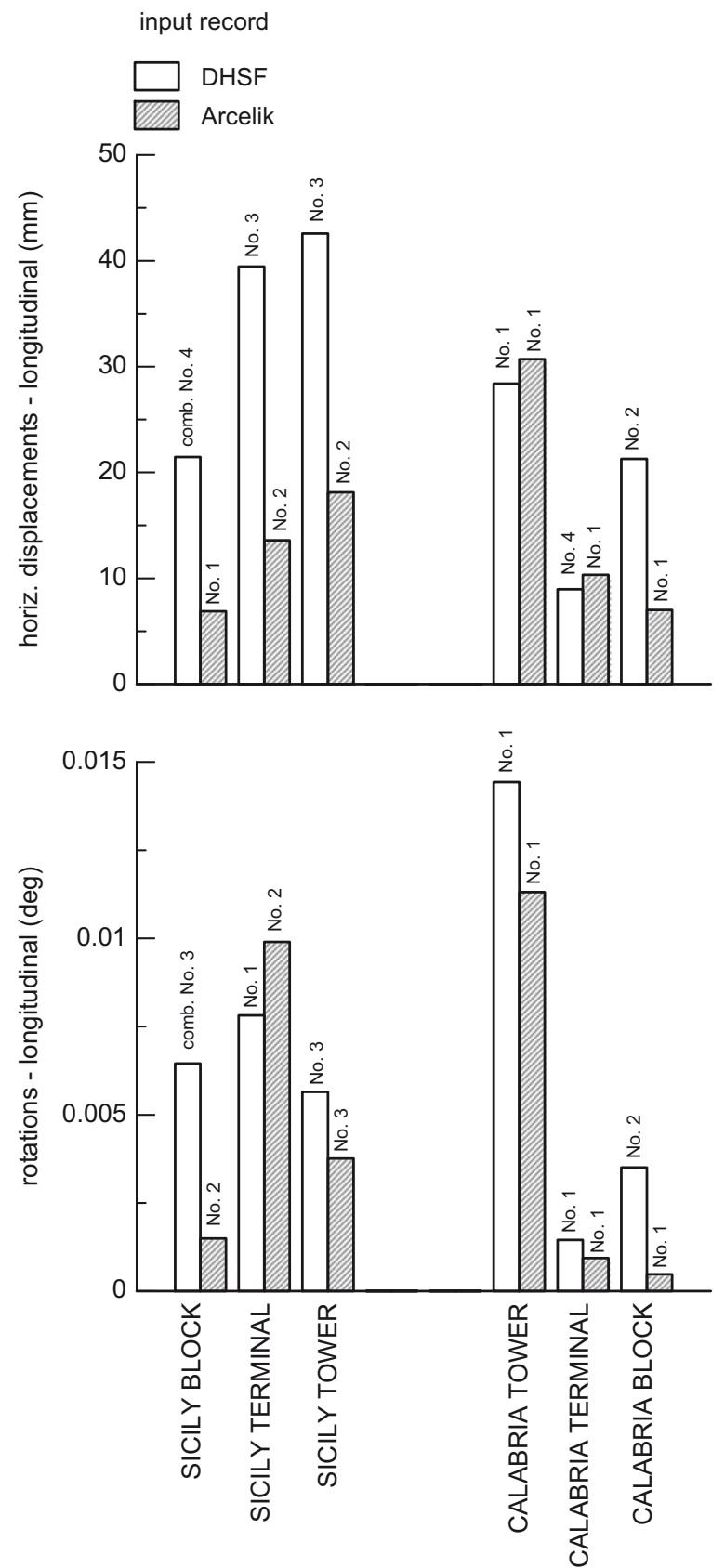

Fig. 17. Computed maximum displacements and rotations in the longitudinal direction.

includes an inclined contact between the upper coastal deposits and the Pezzo Conglomerate.

Fig. 18 shows the lines of equal horizontal displacement for the longitudinal Sicily model, computed after the DHSF earthquake, combination No. 3. It can be seen that in the area next to the anchor block there is a very low displacement gradient, indicating that quite a large volume of soil has displaced in front of the block. Conversely, the horizontal displacements of the tower seem related to its interaction with the adjacent submerged slope, where horizontal displacements have a significant gradient.

\section{Conclusions}

The Messina Strait Bridge was designed in order to show mainly a linear behaviour under the severe design earthquake. For the preliminary design of the substructures, this requirement was checked by carrying out spectral analyses in which the foundation behaviour was simulated through linear equivalent springs, and time-domain dynamic analyses modelling the foundations as linear visco-elastic elements. It was then checked that, under the maximum forces evaluated from these preliminary analyses of the superstructure, the foundations bearing capacity was not attained.

But these analyses alone could provide little information on the actual dynamic response of the soil-structure system, because the linear springs and dashpots were seemingly a poor approximation of the actual non linear and hysteretic behaviour of each soilfoundation system, and because it was not possible to take into account the modification in the seismic motion produced by the dynamic response of the foundation elements and the superstructure. Furthermore, no information could be gained on the actual seismic performance of the foundations that, even if bearing capacity is never attained, nevertheless could accumulate permanent deformations because of the hysteretic nature of soil behaviour.

The additional analyses that form the bulk of this paper were useful to evaluate the soil-structure interaction effects: they provided an insight into the dynamic behaviour of the system and allowed an estimate of the permanent displacement induced in the foundations by the earthquake loading. It was seen that the dynamic behaviour of the soil-foundation system is substantially influenced by both the free-field soil response and the dynamic response of the massive foundation elements; conversely, it is scarcely affected by the dynamic behaviour of the superstructure. This finding may not be general, as it is probably related, on the one hand, to the very significant embedded mass of the foundations and, on the other hand, to the large vibration periods of the superstructure: the first tower period is larger than $2.5 \mathrm{~s}$, while the cable periods are so large that cable forces can be assumed to be applied statically. Of course, the superstructure does influence the analysis results, because the forces that they transmit into the foundation alter the effective stress state in the soil, influencing its mechanical behaviour and contributing to the development of the permanent deformations.

Some of the features that emerged from the present soilstructure interaction analyses could be detected only by including in a single model the soil, the foundation elements and the tower structure. For instance, the evident interaction between the Sicily tower and the submerged sloping shore, that affects the seismic displacements, could not have emerged from a decoupled approach. Also, by neglecting the restraining effects due to the 


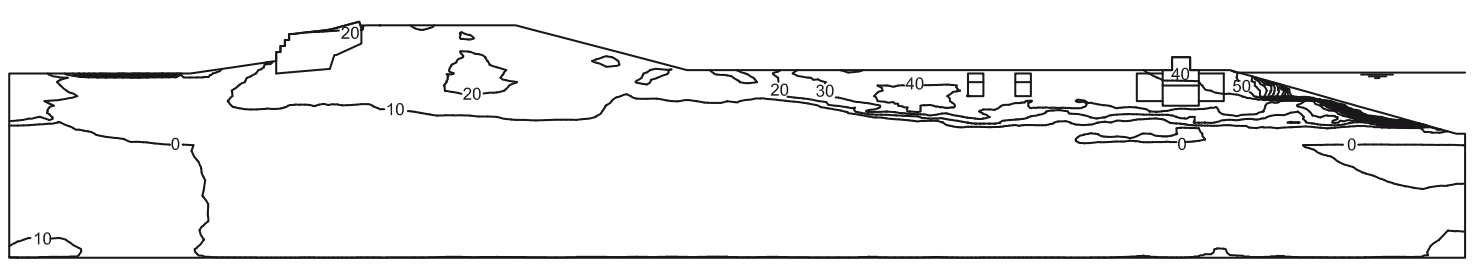

Fig. 18. Contours of horizontal displacement, in mm (positive rightwards) for the longitudinal Sicily model (DHSF record, combination No. 3),

structural model of the tower, that is connected to the elastic spring that simulates the stiffness of the suspension system, the displacements and the rotations of the tower could have been miscalculated.

In addition, from each analysis it was possible to extract the time histories of the displacements and rotation at each contact point between the foundations and the superstructure (namely, displacements along three orthogonal directions and the two rotations in the transverse and longitudinal vertical planes). These time histories were imposed to the base of the three-dimensional global model of the bridge to carry out an additional set of dynamic structural analyses in the time domain, since they constitute a dynamic loading condition that implicitly accounts for the soil-structure interaction analysis.

\section{Acknowledgments}

The authors wish to acknowledge Prof. Michele Jamiolkowski for the many fruitful discussions and suggestions received during the work and Dr. Riccardo Conti for carrying out most of the plane strain dynamic analyses.

\section{Appendix A. Supporting information}

Supplementary data associated with this article can be found in the online version at http://dx.doi.org/10.1016/j.soildyn.2013.05. 005. These data include Google maps of the most important areas described in this article.

\section{References}

[1] Kausel E. Early history of soil-structure interaction. Soil Dynamics and Earthquake Engineering 2010;30:822-32.

[2] Aydinoglu MN. Consistent formulation of direct and substructure methods in nonlinear soil-structure interaction. Soil Dynamics and Earthquake Engineering 1993;12:403-10.

[3] Bielak J, Loukakis K, Hisada Y, Yoshimura C. Domain reduction methods for three-dimensional earthquake modelling in localized regions, Part I: Theory. Bulletin of the Seismological Society of America 2003;93:817-24.
[4] Brancaleoni F, Diana G, Faccioli E, Fiammenghi G, Firth IPT, Gimsing NJ, et al. The Messina Strait Bridge. A challenge and a Dream. CRC Press/Balkema; 2010.

[5] Jamiolkowski M Lo Presti D. Geotechnical characterisation of Holocene and Pleistocene Messina sand and grave deposits. In: Proc. International symposium on characterisation and engineering properties of natural soils, Singapore, Swets and Zeitlinger; 2002, 1087-1119.

[6] Cubrinovski M, Ishihara K. Empirical correction between SPT- $N$ value and relative density for sandy soils. Soils and Foundations 1999;39(5):61-71.

[7] Fioravante V, Giretti D Jamiolkowski M Rocchi GF. Triaxial tests on undisturbed gravelly soils from the Sicilian shore of the Messina Strait. submitted to Bulletin of Earthquake Engineering; (2012).

[8] Bolton MD. The strength and dilatancy of sands. Géotechnique 1986;36 (1):65-78.

[9] Castro G. Liquefaction and cyclic mobility of saturated sands. Journal of the Geotechnical Engineering Division, ASCE 1975;101(No. GT6):551-69.

[10] Jaky J. Pressure in Soils, II ICSMFE, London, 1; 1948, 103-107.

[11] Mesri G, Castro A. The $C_{\alpha} / C_{C}$ concept and $K_{0}$ during secondary compression. Closure Journal of the Geotechnical and Engineering Division, ASCE 1989;115 (2):273-7.

[12] Seed HB, Idriss IM, Makdisi F, Banerjee N. Representation of irregular stress time histories by equivalent uniform stress series in liquefaction analyses. Rep. no. UCB/EERC75-29, Earthquake Engrg. Res. Ctr., University of California, Berkeley, Calif.; 1975.

[13] Liu AH, Stewart JP, Moriwaki Y. Equivalent number of uniform stress cycles for soil liquefaction analysis. Journal of Geotechnical and Geoenvironmental Engineering 2001;127(No.12):1017-26.

[14] Schnabel, PB, Lysmer, J, Seed, HB. SHAKE, a computer program for earthquake response analysis of horizontally layered sites. Report: Earthquake Engineering Research Center, University of California, Berkeley; 1972.

[15] Roesset JM. Soil amplification of earthquakes. In: Desai CS, Christian. JT, editors. Numerical methods in geotechnical engineering. New York: Mc Graw-Hill; 1977. p. 639-82.

[16] Gazetas G. Foundation vibrations. In: Fang. HY, editor. Foundation engineering handbook, 2nd edition. New York: Van Nostrand Reinhold; 1990. p. 553-93.

[17] Masing, G. Eigenspannungen und Verfertigung bim Messing. In: Proceedings second international congress on applied mechanics, Zurich; 1926.

[18] Itasca. FLAC: Fast Lagrangian Analysis of Continua v.5.0 User's Manual. ITASCA, USA; 2005.

[19] Callisto L, Soccodato FM. Seismic design of flexible cantilevered retaining walls. Journal of Geotechnical and Geoenvironmental Engineering 2010;136 (No. 2):344-54 February 2010.

[20] Tanaka Y, Kudo Y, Yoshida Y, Ikemi M. A study on the mechanical properties of sandy gravel-dynamic properties of reconstituted samples. Central Research Institute of Electric Power Industry, Report 1987;U87019.

[21] Seed, HB, Idriss, IM. Soil moduli and damping factors for dynamic analysis. Report no. EERC 70-10, University of California, Berkeley; 1970

[22] Joyner WB, Chen ATF. Calculation of nonlinear ground response in earthquakes. Bulletin of the Seismological Society of America 1975;65(5):1315-36.

[23] Croce P, Flora A, Modoni G. Jet grouting. Tecnica, progetto e controllo. Hevelius Edizioni, Benevento, 2004.

[24] Lysmer J, Kuhlemeyer RL. Finite dynamic model for infinite media. Journal of Engineering Mechanics 1969;95(EM4):859-77. 